\title{
Synthesis and characterization of CdS nanocrystals embedded in germanate glasses
}

\author{
S. El-Rabaie - T. A. Taha $\cdot$ A. A. Higazy
}

Received: 29 October 2012/ Accepted: 28 December 2012/Published online: 12 January 2013

(C) The Author(s) 2013. This article is published with open access at Springerlink.com

\begin{abstract}
Cadmium sulfide nanoparticles were grown in $\mathrm{Na}_{2} \mathrm{O}-\mathrm{GeO}_{2}$ glass matrix by a diffusion-controlled phase decomposition of over-saturated solid solution. The structural properties of CdS nanocrystals have been studied by means of X-ray diffraction (XRD), transmission electron microscopy (TEM), optical absorption and electrical conductivity. The existence of CdS nanocrystals was confirmed by XRD and TEM, also its crystallite sizes are obtained. The average CdS crystallite sizes calculated from XRD analysis for the different heat-treatment conditions are found in the range between 23.7 and $48.8 \mathrm{~nm}$; however, the average CdS crystallite sizes obtained from TEM micrographs are found in the range between 17 and $63 \mathrm{~nm}$. The band gap energy $E_{\mathrm{opt}}$ and the activation energy $E_{\mathrm{g}}$ for the electrical conductivity have been increased with decrease in the particle size; however, the Urbach energy $\Delta E$ decreases with decreasing the nanocrystal size.
\end{abstract}

Keywords Nanostructures - Glasses - Optical properties · Electrical conductivity

\section{Introduction}

Cadmium sulfide, a technologically important material, has aroused some interest in recent years. In the early 1980s,

S. El-Rabaie · T. A. Taha ( $₫)$

Physics and Engineering Mathematics Department, Faculty of Electronic Engineering, Menufiya University, Menouf 32952, Egypt

e-mail: taha.hemida@yahoo.com

\section{A. A. Higazy}

Physics Department, Faculty of Science, Menufiya University, Shebin El-Koom 32511, Egypt it was found that semiconductor nanocrystals embedded in a wide-gap matrix of oxide glass represented threedimensionally confined quantum wells for electronic excitations (electrons, holes, excitons) (Ekimov et al. 1980; Ekimov and Onushchenko 1981; Efros and Efros 1982). The development of the technology for growing of nanocrystals of various semiconductor compounds via the process of diffusion-controlled phase decomposition of oversaturated solid solution (Golubkov et al. 1981) has opened the door for intensive investigations of their linear, nonlinear and electro-optical properties.

The purpose of this paper is to grow and characterize the novel system of CdS nanoparticles embedded in germanate glass matrix. In this work also, it is intended to study the effect of CdS nanocrystal sizes on the optical and electrical properties of the present sodium germanate glass system. The prepared glass samples were characterized by differential thermal analysis (DTA), X-ray diffraction (XRD) and transmission electron microscopy (TEM).

\section{Experimental}

In this work, we have prepared a novel system of $\mathrm{CdS}$ nanoparticles embedded in sodium germanate glass matrix. This system is $40 \mathrm{Na}_{2} \mathrm{O}-60 \mathrm{GeO}_{2}: 3 \mathrm{wt} \% \mathrm{CdS}$. The raw materials used in preparation are $\mathrm{Na}_{2} \mathrm{CO}_{3}, \mathrm{GeO}_{2}$ and $\mathrm{CdS}$ reagent grades. They were weighted, mixed and stirred many times to obtain homogeneous mixture. The mixture was put in a porcelain crucible and inserted in an electric furnace held at $1,498 \mathrm{~K}$ for $2 \mathrm{~h}$. Then, the melt has poured into two mild steel split mould in air. A DTA measurement for the asquenched glass sample was performed by a micro differential thermal analyzer (Shemadzu-DT30). DTA allows us to identify the glass transition temperature $\left(T_{\mathrm{g}}\right)$ and the glass 
crystallization temperature $\left(T_{\mathrm{c}}\right)$ which are needed to select the values of annealing temperatures required to obtain different sizes of nanoparticles. In the present work, we have found the values of $T_{\mathrm{g}}$ and $T_{\mathrm{c}}$ are 831 and $935 \mathrm{~K}$, respectively, accordingly the produced glass samples are heattreated at $853,873,883$ and $893 \mathrm{~K}$ for different time periods (1-9 h) to grow different sizes of nanoparticles.

The XRD analysis was performed by a Philips Pw 1373 $\mathrm{X}$-ray diffractometer with Cu radiation $(\lambda=1.542 \AA)$. TEM of type (JEOL-200CX) Japan was employed to examine the crystallinity and the particle size of the heat-treated glass samples. The optical absorption spectra were recorded using a Jasco V-530 UV-Vis spectrophotometer in the wavelength region $200-1,000 \mathrm{~nm}$ at room temperature. For the measurements of dc electrical conductivity, electrodes were formed by brush painting silver paste. The dc conductivity was measured as a function of temperature, using a springloaded sample holder in a wire-wound cylindrical furnace. All our dc electrical conductivity measurements were made using a Keithley electrometer model 616, with a smoothing adjustable power supply $(0-1 \mathrm{kV})$. A fixed voltage of $200 \mathrm{~V}$ was applied. The temperature of the specimen was measured by means of a chromel-alumel thermocouple.

The dc electrical conductivity $\left(\sigma_{\mathrm{dc}}\right)$ of each glass specimen was then calculated using the formula:

$\sigma=\frac{L}{R A}$

where $L$ is the thickness of the sample $(\mathrm{cm}), A$ is the area of the electrode $\left(\mathrm{cm}^{2}\right)$ and $R$ is the resistance $(\Omega)$.
Fig. 1 XRD patterns of glass samples heat-treated at $853 \mathrm{~K}$ for different annealing times
Fig. 2 XRD patterns of glass samples heat-treated at $873 \mathrm{~K}$ for different annealing times
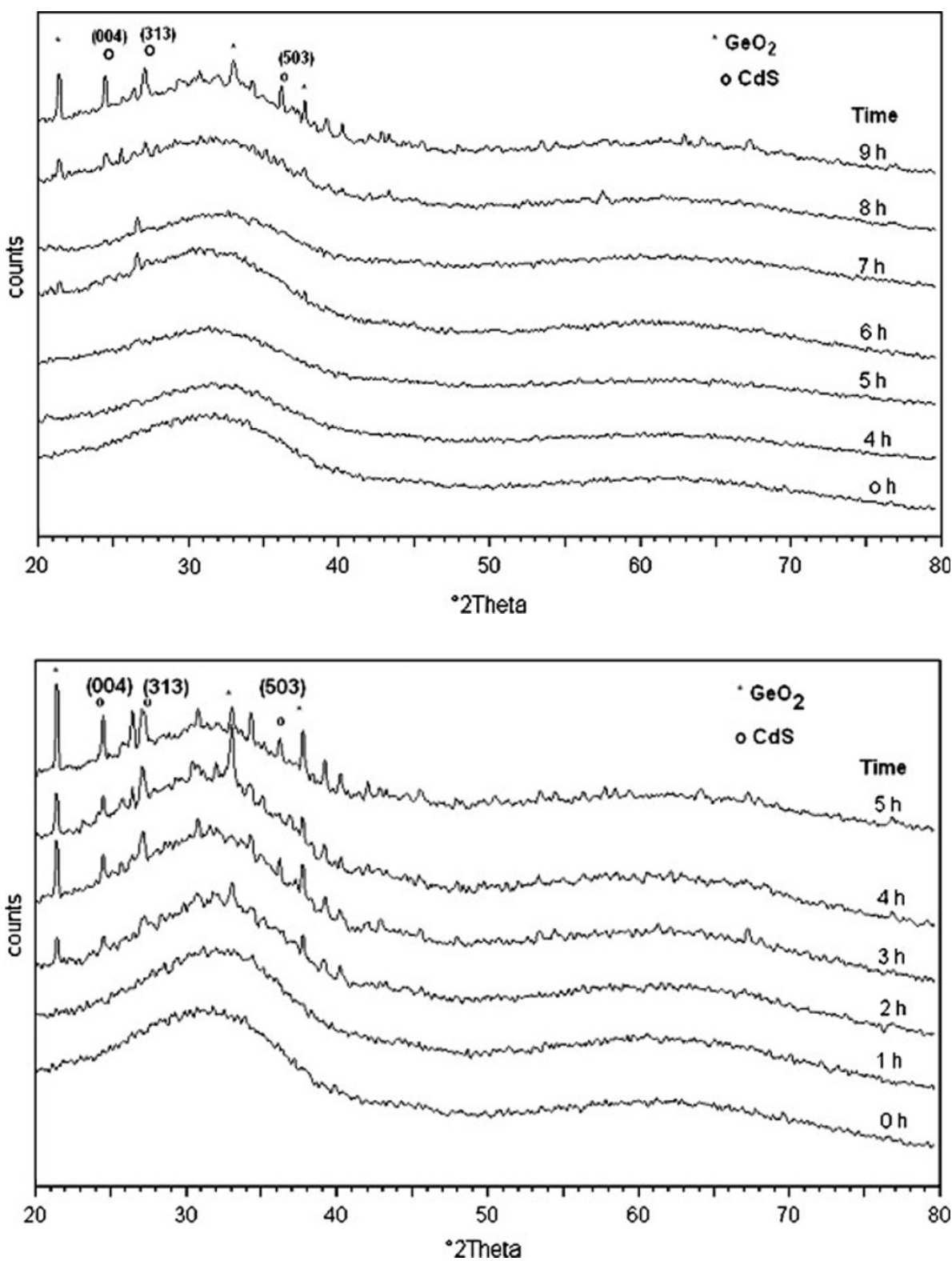


\section{Results and discussion}

$\mathrm{XRD}$ and TEM analysis

Figures 1, 2, 3 and 4 show the XRD patterns for the glass samples $\left(40 \mathrm{Na}_{2} \mathrm{O}-60 \mathrm{GeO}_{2}: 3 \mathrm{wt} \% \mathrm{CdS}\right)$ heat-treated at $853,873,883$ and $893 \mathrm{~K}$ for different annealing times (1-9 h). The XRD patterns show diffraction lines compatible with the diffraction lines of orthorhombic bulk CdS and hexagonal $\mathrm{GeO}_{2}$ crystal at the surface of the nanoparticles according to [JCPDS 47-1179] and [JCPDS 83-0548], respectively. This result indicates that our quenching method leads to formation and crystallization of $\mathrm{CdS}$ nanoparticles which are covered by $\mathrm{Ge}-\mathrm{O}$ bonds at the surface of the nanoparticles (Swelm et al. 2011).
We have calculated the mean sizes for the nanoparticles embedded in glass from full width at half maximum intensity of XRD peaks according to the Debye-Scherrer (Guinier 1963) equation:

$D=\frac{0.9 \lambda}{\beta \cos \theta}$

where $D$ is the crystallite size, $\beta$ is the half-width of diffraction peak in radians, $\lambda$ is the $\mathrm{X}$-ray wavelength and $\theta$ is the angle of diffraction.

According to Figs. 1, 2, 3, 4 and Eq. 2, the calculated values of the average $\mathrm{CdS}$ particle size, $D$, were found to have sizes ranging from 23.7 to $48.8 \mathrm{~nm}$ for the studied glass samples heat-treated at $853,873,883$ and $893 \mathrm{~K}$ for different annealing times ranging from 1 to $9 \mathrm{~h}$ (see Table 1).
Fig. 3 XRD patterns of glass samples heat-treated at $883 \mathrm{~K}$ for different annealing times

Fig. 4 XRD patterns of glass samples heat-treated at $893 \mathrm{~K}$ for different annealing times
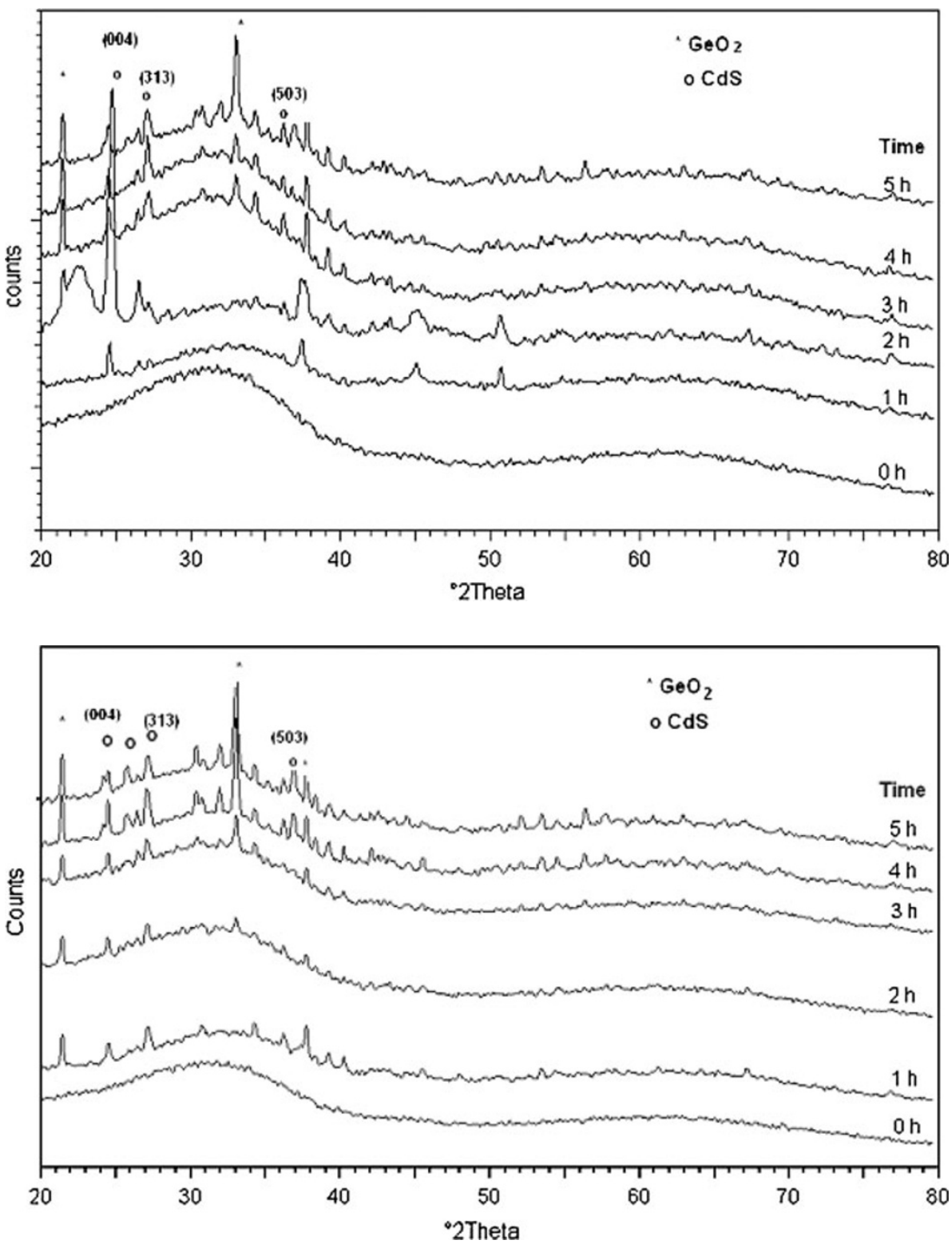

'2Theta 
Table 1 The average CdS crystallite sizes obtained from the XRD and TEM analysis, optical band gap $\left(E_{\mathrm{opt}}\right)$ and Urbach energy $(\Delta E)$ of the $\left(40 \mathrm{Na}_{2} \mathrm{O}-60 \mathrm{GeO}_{2}: 3 \mathrm{wt} \% \mathrm{CdS}\right)$ heat-treated at different temperatures for different times

\begin{tabular}{|c|c|c|c|c|c|}
\hline \multirow[t]{2}{*}{$\begin{array}{l}\text { Annealing } \\
\text { temperature }(\mathrm{K})\end{array}$} & \multirow[t]{2}{*}{ Time (h) } & \multicolumn{2}{|c|}{$\begin{array}{l}\text { Average particle } \\
\text { size }(\mathrm{nm})\end{array}$} & \multirow[t]{2}{*}{$E_{\text {opt }}(\mathrm{eV})$} & \multirow[t]{2}{*}{$\Delta E(\mathrm{eV})$} \\
\hline & & XRD & TEM & & \\
\hline \multirow[t]{4}{*}{853} & 6 & 24.8 & 17 & 3.14 & 1.63 \\
\hline & 7 & 28.3 & 22 & 3.09 & 1.13 \\
\hline & 8 & 30.93 & 25 & 3.32 & 0.85 \\
\hline & 9 & 35.3 & 31 & 3.28 & 0.83 \\
\hline \multirow[t]{4}{*}{873} & 2 & 23.7 & 18 & 3.39 & 0.81 \\
\hline & 3 & 26.4 & 28 & 3.29 & 0.92 \\
\hline & 4 & 34.8 & 40 & 3.21 & 1.07 \\
\hline & 5 & 37.8 & 43 & 3.19 & 1.3 \\
\hline \multirow[t]{5}{*}{883} & 1 & 27.25 & - & 3.37 & 0.58 \\
\hline & 2 & 30.1 & 25 & 3.34 & 0.62 \\
\hline & 3 & 32.2 & 33 & 3.16 & 1 \\
\hline & 4 & 35.6 & 43 & 3.14 & 1.66 \\
\hline & 5 & 39.4 & 50 & 3.12 & 1.21 \\
\hline \multirow[t]{5}{*}{893} & 1 & 29.5 & - & 3.30 & 0.84 \\
\hline & 2 & 33.1 & 30 & 3.33 & 0.53 \\
\hline & 3 & 36.2 & 41 & 3.32 & 0.60 \\
\hline & 4 & 41.9 & 50 & 3.29 & 0.62 \\
\hline & 5 & 48.8 & 63 & 3.27 & 0.81 \\
\hline
\end{tabular}

Figure 5a-d shows the TEM micrographs for the glass samples heat-treated at $853,873,883$ and $893 \mathrm{~K}$ for different times 7, 4, 2 and $3 \mathrm{~h}$, respectively.

The estimated average crystallite size based on the electron microscope analysis for the different phases exists in the annealed samples at $853,873,883$ and $893 \mathrm{~K}$ for different times that are tabulated in Table 1, where the average particle size varies from 17 to $63 \mathrm{~nm}$ depending on the annealing time.

From XRD analysis, the decrease in the broadening of the diffraction peaks with increasing the annealing time and annealing temperature is due to the increase in nanoparticle size, also from TEM micrographs it is observed that the size of the nanoparticles increases with increasing the annealing time (Fig. 6a-d) and annealing temperature.

The obtained dependence of CdS particle size (Fig. 6a-d) on the heat-treatment time cannot be described by the relationship $R \sim t^{1 / 2}$ (a "normal growth" usually preceding the coalescence (Ekimov 1996)) or by the relationship $R \sim t^{1 / 3}$. In the present study, the growth can be represented as $R_{\mathrm{XRD}} \sim t^{0.056}$ for low annealing temperature $(853 \mathrm{~K})$ and $R_{\mathrm{XRD}} \sim t^{0.88}$ for high annealing temperature $(893 \mathrm{~K})$. However, for the obtained nanoparticle size using TEM method the growth rate showed $R_{\mathrm{TEM}} \sim t^{0.075}$ and $R_{\mathrm{TEM}} \sim t^{0.18}$ at the same temperatures above (Fig. 6a-d). Therefore, the mechanism of the growth of $\mathrm{CdS}$ semiconductor nanocrystals in germanate glasses calls for further investigation.

\section{UV-Vis absorption spectra}

The change of the optical absorption of heat-treated samples is due to increasing the number of crystalline nuclei of the same size at the initial stage of growth; also changes of shapes of absorption spectra are due to changes of positions of quantum levels with growth of nanoparticles (Burda et al. 2005).

Figure 7 shows the absorption spectra for the glass samples heat-treated at $873 \mathrm{~K}$ for different annealing times 2, 3, 4 and $5 \mathrm{~h}$, respectively. From inspection of this figure it is observed that the values of the absorption band-edge wavelength, $\lambda_{\text {cut off }}$, seem to move generally, towards the longer wavelengths as the annealing time is increased, i.e., towards the red shift.

The values of $E_{\text {opt }}$ were determined for the all heattreated $\left(40 \mathrm{Na}_{2} \mathrm{O}-60 \mathrm{GeO}_{2}: 3 \mathrm{wt} \% \mathrm{CdS}\right)$ glass samples at $853,873,883$ and $893 \mathrm{~K}$ for different times ranging from 1 to $9 \mathrm{~h}$ (using Davis-Mott relation Tauc et al. 1966; Davis and Mott 1970) by extrapolation to zero absorption in the $(\alpha \hbar \omega)^{2}$ versus $\hbar \omega$ plots in (Fig. 8 as an example).

$\alpha(\omega)=B\left[\left(\hbar \omega-E_{\text {opt. }}\right)^{n} / \hbar \omega\right]$

where $B$ is a constant, $E_{\text {opt. }}$ is the optical band gap energy and $n$ is a number which characterizes the transition process ( $n=1 / 2$ for direct allowed transition).

The obtained values of $E_{\text {opt }}$ show a decrease with increasing the annealing time and annealing temperature but with a slow rate at low annealing temperatures; on the other hand at higher annealing temperature, the rate of decreasing the $E_{\mathrm{opt}}$ increases with increasing the annealing time (see Table 1). The low rate of changing the band gap at low temperatures may be due to the reduction of intrinsic defects at the nanoparticles glass interface (Mathieu et al. 1995) and can be explained as following (Swelm et al. 2011). At these short times, we have two opposite effects on the energy of the absorption edge (1) effect of growing which leads to a shift of absorption to lower energy side and (2) the reduction of intrinsic defects which cause a slight shift to higher energy side. These two effects lead to the change in the energy of the absorption edge which is small. Then, the obtained results imply that the increase in nanoparticle size with increasing annealing temperature and annealing time leads to a decrease in the band gap energy.

The width of the band tails (Urbach energy $\Delta E$ ) associated with valence and conduction bands was believed to be originated from electron transition between localized states, where the density of these localized states is exponentially dependent on energy (Tauc and Zanini 1977). Values of $\Delta E$ for the heat-treated glass samples at 853,873 , 883 and $893 \mathrm{~K}$ for different times ranging from 1 to $9 \mathrm{~h}$ are 

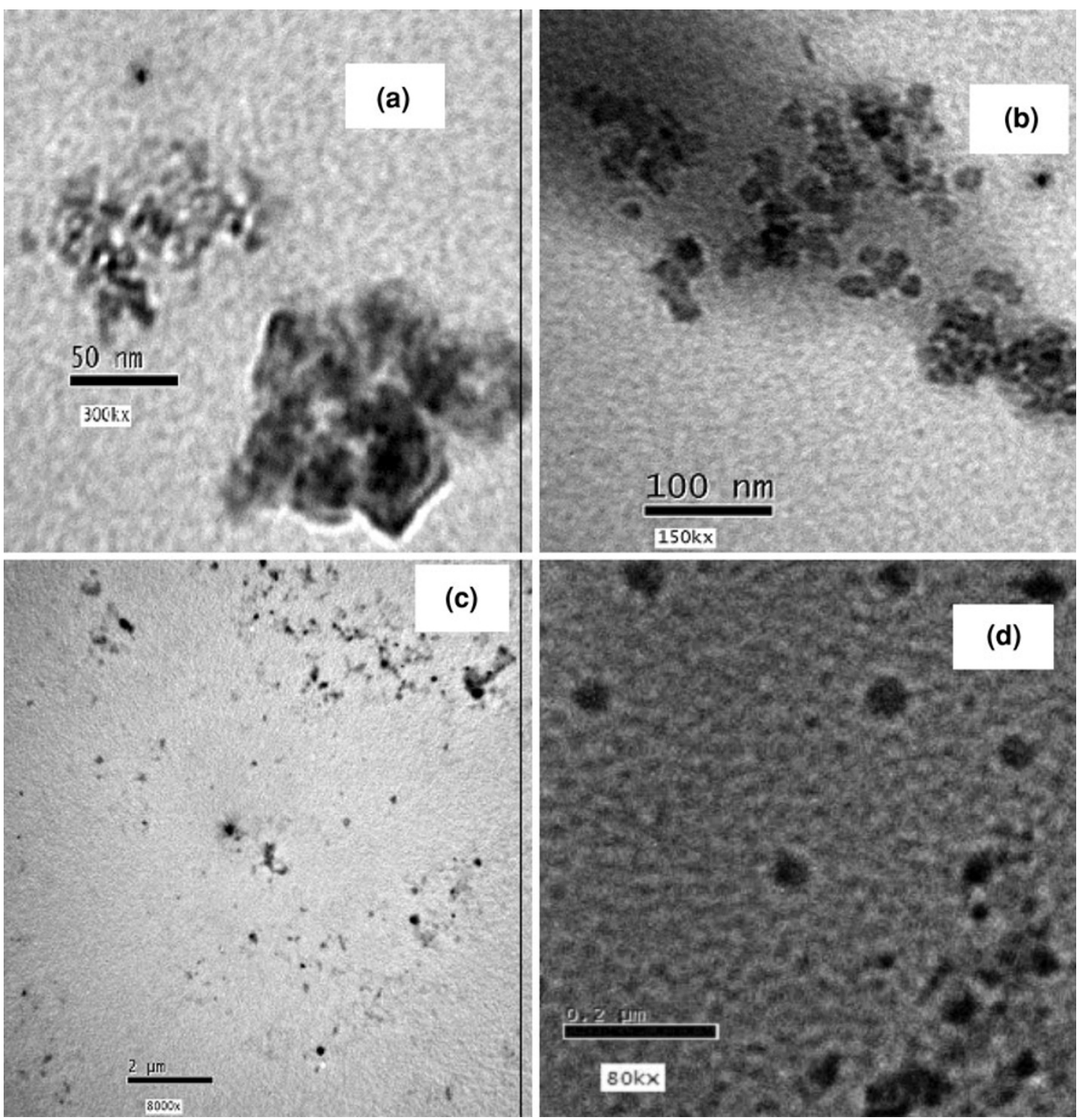

Fig. 5 a-d TEM micrographs for the glass samples heat-treated at 853, 873, 883 and $893 \mathrm{~K}$ for different times 7, 4, 2 and 3 h, respectively

determined from the inverse slopes of $\ln \alpha(\omega)$ versus $\hbar \omega$ plots according to the following Urbach equation which are shown in Fig. 9 as an example.

$\alpha(\omega)=\alpha^{\prime}(\omega) \mathrm{e}^{(\hbar \omega / \Delta E)}$

where $\alpha^{\prime}(\omega)$ is constant and $\Delta E$ is the width of the band tails energy.

The Urbach energy was used to characterize the degree of disorderness (which would depend on the thermal history of the samples) in amorphous and crystalline systems, materials with larger Urbach energy would have greater tendency to convert weak bonds into defects ( $\mathrm{Pal}$ et al. 2000; Levy et al. 1989). It is observed that the Urbach energy for all heat-treated glass samples increases as the annealing time and annealing temperature increases (see
Table 1), suggesting that there is an increase in the defect concentration.

The DC electrical conductivity

The temperature dependence of the dc electrical conductivity, $\sigma_{\mathrm{dc}}$, for the heat-treated $\left(40 \mathrm{Na}_{2} \mathrm{O}-60 \mathrm{GeO}_{2}: 3 \mathrm{wt} \%\right.$ $\mathrm{CdS})$ glass samples at constant temperature $(873 \mathrm{~K})$ for different duration times (2, 3, 4 and $5 \mathrm{~h}$ ) are calculated from the measured voltage and current values.

The dependence of the measured dc electrical conductivity on the reciprocal absolute temperature $(1 / T)$ is well represented by Arrhenius relation (Shihub and Gould 1995):

$\sigma=\sigma_{0} \mathrm{e}^{-E_{\mathrm{g}} / k T}$

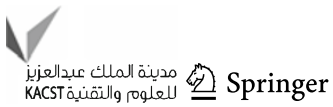



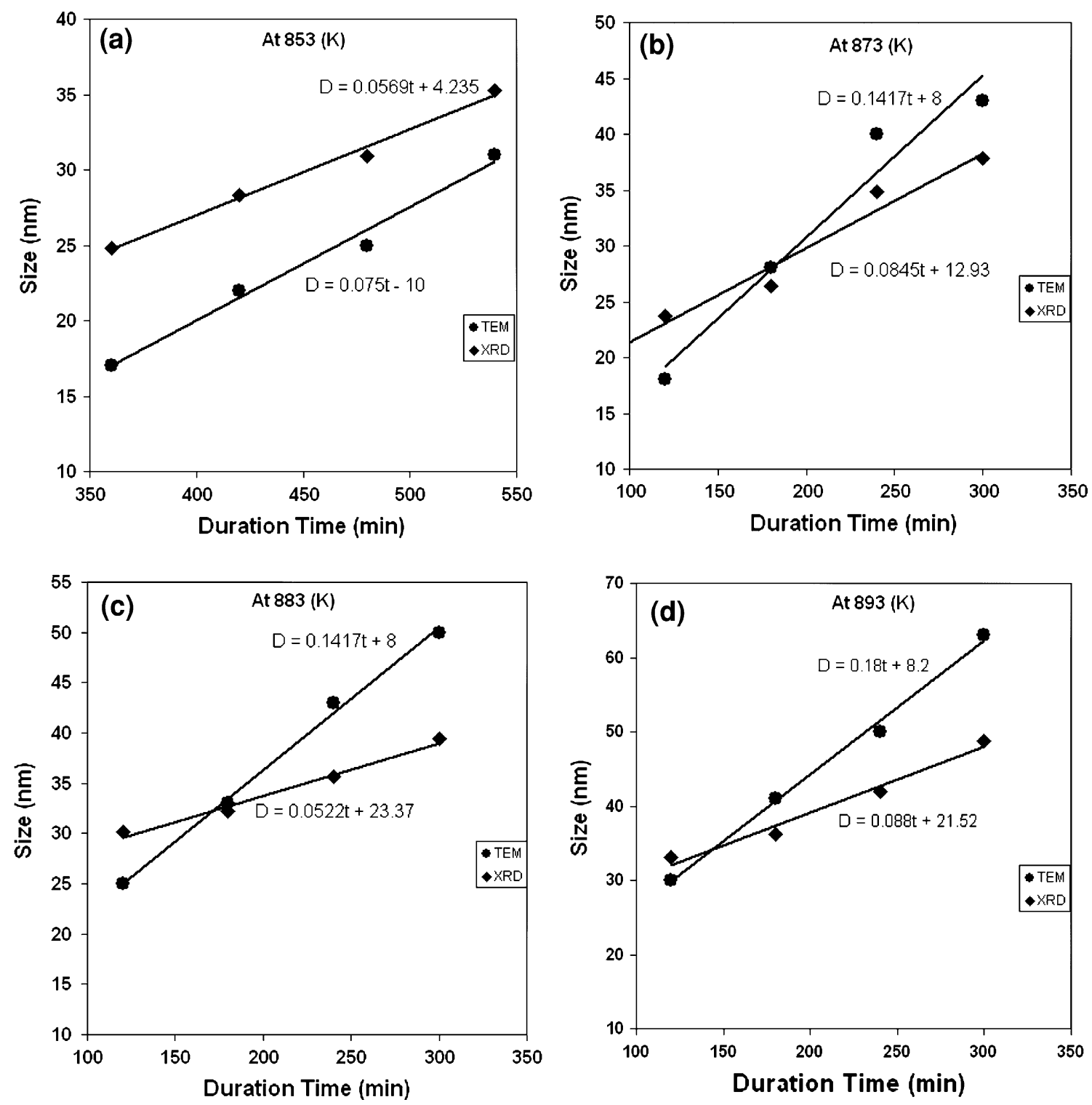

Fig. 6 a-d The nanoparticle average sizes obtained from XRD and TEM analyses as a function of time at annealing temperatures $853,873,883$ and $893 \mathrm{~K}$

where, $\sigma$ is the electrical conductivity, $\sigma_{0}$ represents the value of $\sigma$ at $T=0, k$ Boltzmann's constant and $E_{\mathrm{g}}$ is the activation energy.

The variation of $\log \sigma_{\mathrm{dc}}$ with the reciprocal of the absolute temperature $\left(T^{-1}\right)$ is shown in Fig. 10 for the glass-ceramic samples annealed at $873 \mathrm{~K}$ for different times $(2-5 \mathrm{~h})$. From inspection of this figure, it is observed that $\log \sigma_{\mathrm{dc}}$ versus $T^{-1}$ gives good straight lines with different slopes at high temperatures for all the present annealed glass samples. The activation energies were calculated from the slopes of $\log \sigma_{\mathrm{dc}}$ versus $T^{-1}$.
The variation of the activation energy, $E_{\mathrm{g}}$, for the $40 \mathrm{Na}_{2} \mathrm{O}$ $60 \mathrm{GeO}_{2}: 3$ wt $\%$ CdS glass-ceramic samples annealed at $873 \mathrm{~K}$ for different annealing times is shown in Fig. 11.

From inspection of this figure, one can observe that the activation energy decreases from 0.061 to $0.028 \mathrm{eV}$ as the nanoparticle size increases.

This obtained $E_{\mathrm{g}}$ showed higher energy values than that obtained for the as-quenched glass samples which is probably expected to be almost due to the electronic transitions between discrete energy levels of the split valence and conduction bands in CdS nanocrystals and the energy gap should be increased with decreasing the $\mathrm{CdS}$ 


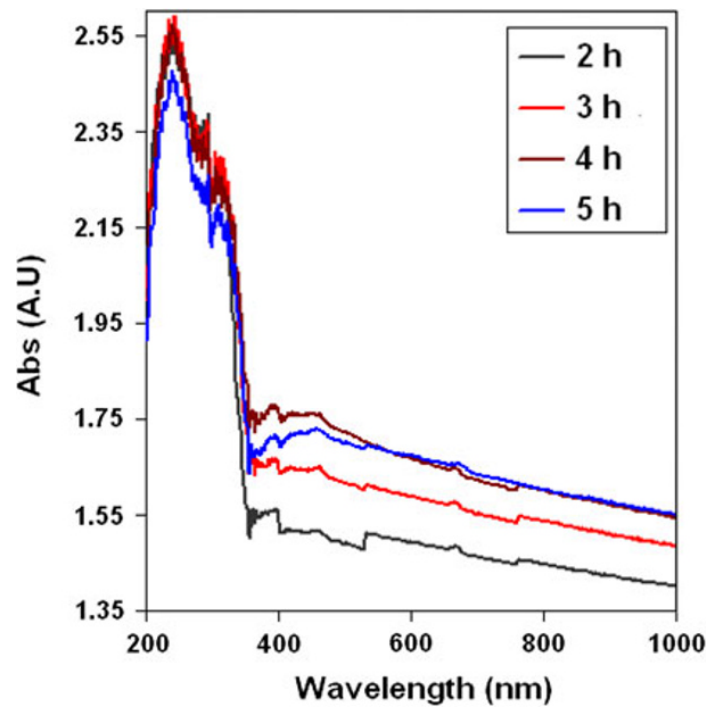

Fig. 7 The optical absorption spectra for the $\left(40 \mathrm{Na}_{2} \mathrm{O}-60 \mathrm{GeO}_{2}: 3\right.$ wt $\% \mathrm{CdS}$ ) glass samples annealed at $873 \mathrm{~K}$ for different times 2, 3, 4 and $5 \mathrm{~h}$, respectively, as an example

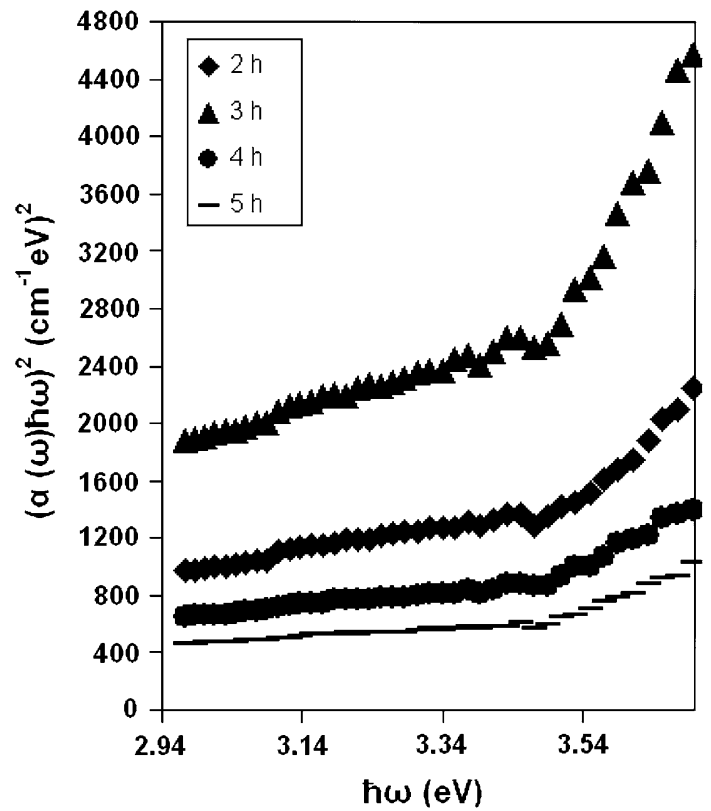

Fig. 8 The variation of $(\alpha \hbar \omega)^{2}$ with photon energy $(\hbar \omega)$ for the glass samples annealed at $873 \mathrm{~K}$ for different times 2, 3, 4 and $5 \mathrm{~h}$, respectively, as an example

nanoparticle sizes (Alivisatos 1996a, b; Brus 1991; Gaponenko 1998) and the contribution of $\mathrm{Na}^{+}$ion to the conduction is very small.

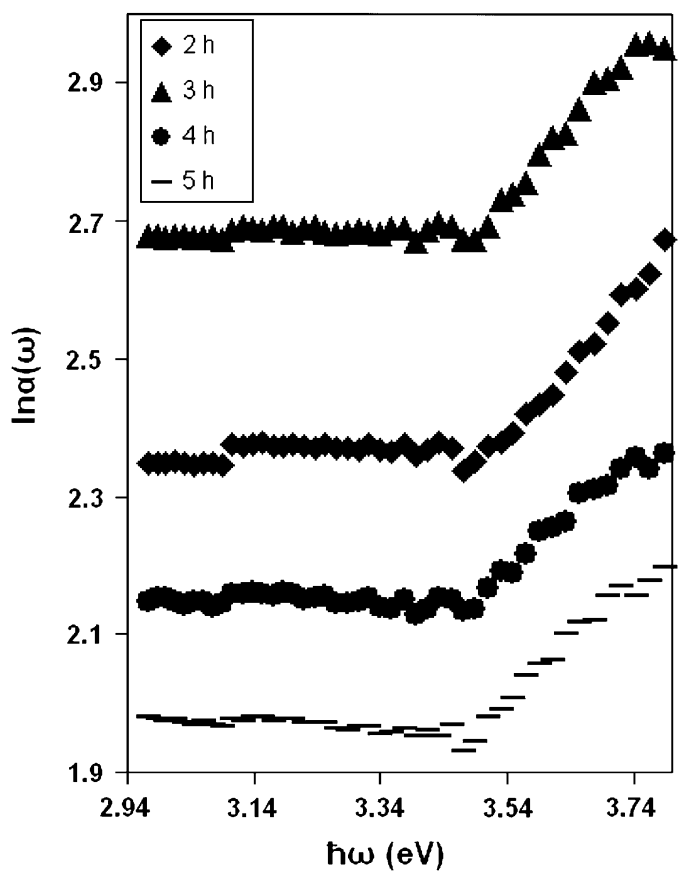

Fig. 9 The variation of $\ln \alpha$ with photon energy $(\hbar \omega)$ for the glass samples annealed at $873 \mathrm{~K}$ for different times $2,3,4$ and $5 \mathrm{~h}$, respectively, as an example

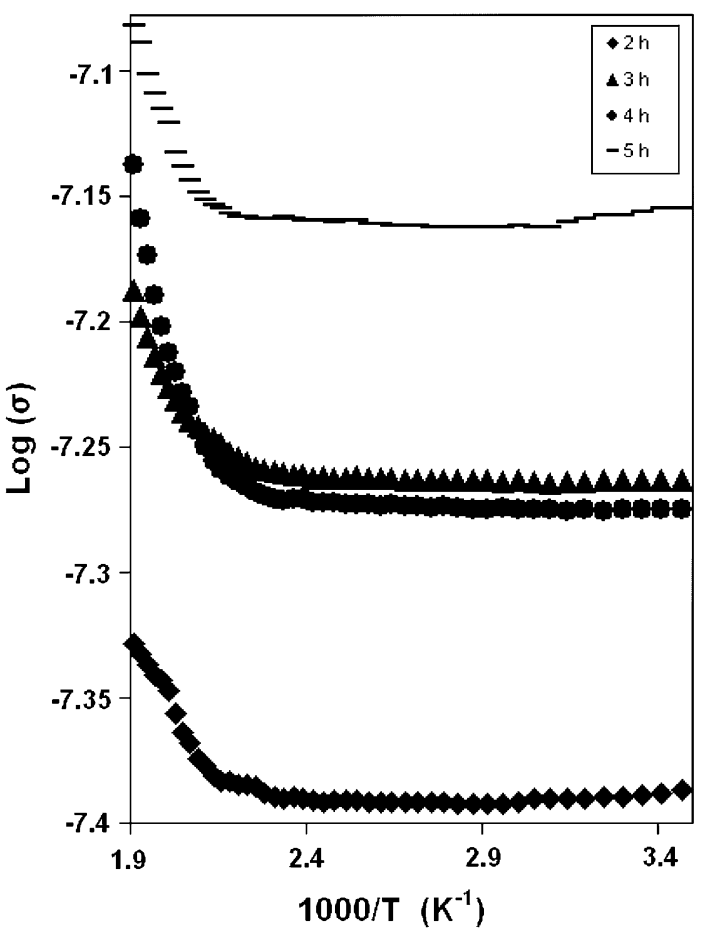

Fig. 10 The variation of $\log \sigma$ with $1,000 / T\left(\mathrm{~K}^{-1}\right)$ for the glassceramic samples annealed at $873 \mathrm{~K}$ for different annealing times $(2,3,4$ and $5 \mathrm{~h})$ 
Fig. 11 The size dependence of the activation energy for the glass-ceramic samples annealed at $873 \mathrm{~K}$ for different annealing times $(2,3,4$ and $5 \mathrm{~h})$

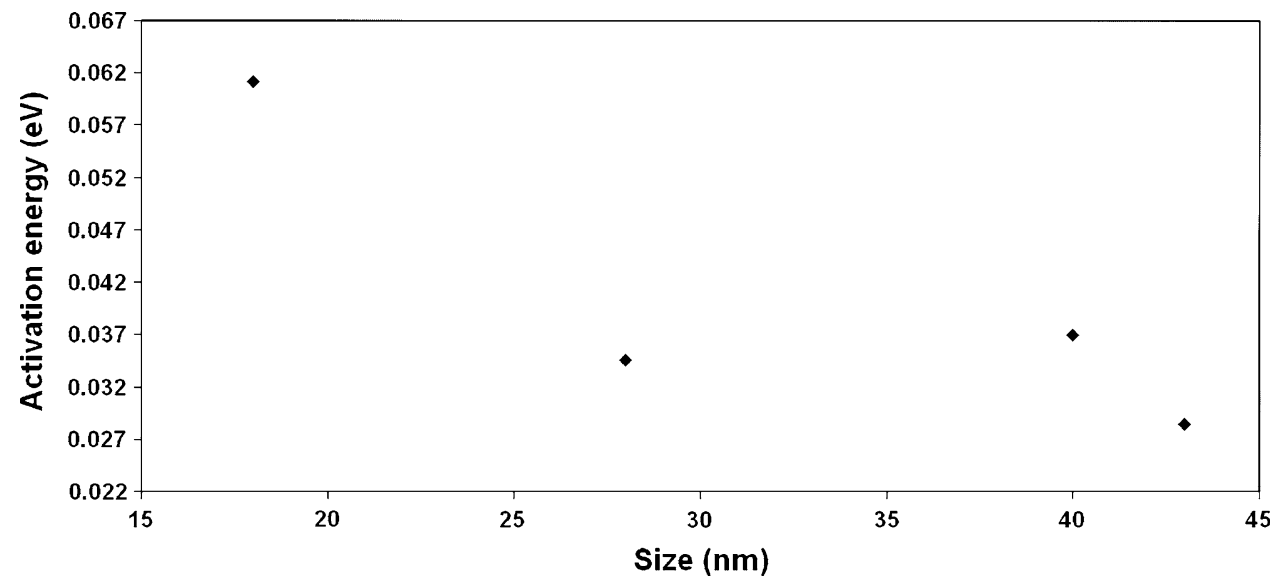

\section{Conclusion}

We have reported the growth of a novel system of $\mathrm{CdS}$ nanocrystals in sodium germanate $\left(40 \mathrm{Na}_{2} \mathrm{O}-60 \mathrm{GeO}_{2}\right)$ glass matrix. The prepared $\mathrm{CdS}$ nanoparticles in glass matrix are characterized by DTA, XRD and TEM. The nanoparticle sizes are calculated using XRD patterns and TEM micrographs, which are found to vary from 17 to $63 \mathrm{~nm}$.

The optical energy gap $E_{\text {opt }}$ of CdS nanoparticles showed a decrease in its values with increasing the nanoparticle size also, the electrical activation energy $E_{\mathrm{g}}$ for the same samples showed the same nanoparticles size dependence; this may be due to a splitting of both the valence and conduction bands into a series of subbands, i.e., the energy band in nanocrystals becomes discrete. However, the Urbach energy $\Delta E$ increases as the nanoparticle size increases, this behavior suggests that there is a tendency to form clusters with increasing the value of nanoparticle size.

Open Access This article is distributed under the terms of the Creative Commons Attribution License which permits any use, distribution, and reproduction in any medium, provided the original author(s) and the source are credited.

\section{References}

Alivisatos AP (1996a) Perspectives on the physical chemistry of semiconductor nanocrystals. J Phys Chem 100:13226

Alivisatos AP (1996b) Semiconductor clusters, nanocrystals and quantum dots. Science 271:933

Brus LE (1991) Quantum crystallites and nonlinear optics. Appl Phys A 53:465

Burda C, Chen X, Narayanan R, El-Sayed MA (2005) Chemistry and properties of nanocrystals of different shapes. Chem Rev $105: 1025$
Davis EA, Mott NF (1970) Conduction in non-crystalline systems V. Conductivity, optical absorption and photoconductivity in amorphous semiconductors. Philos Mag 22:903

Efros AlL, Efros AL (1982) Interband absorption of light in a semiconductor sphere. Sov Phys Semicond 16:772

Ekimov A (1996) Growth and optical properties of semiconductor crystals in glass matrix. J Lumin 70:1

Ekimov AI, Onushchenko AA (1981) Quantum size effect in threedimensional microscopic semiconductor crystals. Sov JETP Lett $34: 345$

Ekimov AI, Onushenko AA, Tzehomskii VA (1980) Exciton light absorption by $\mathrm{CuCl}$ microcrystals growth in a glass matrix. Sov Phys Chem Glass (Fiz. Khim. Stekla) 6:511

Gaponenko K (1998) Optical properties of semiconductor nanocrystals. Cambridge University Press, Cambridge

Golubkov VV, Ekimov AI, Onushchenko AA, Tsehomskii VA (1981) Kinetiks of $\mathrm{CuCl}$ microcrystals growth in a glass matrix. Sov Phys Chem Glass 7:397

Guinier A (1963) X-ray diffraction in crystals, imperfect crystals, and amorphous bodies. W.H. Freeman, San Francisco

Levy M, Duclot JM, Rousseau F (1989) V2O5-based glasses as cathodes for lithium batteries. J Power Sources 26:381

Mathieu H, Richard T, Allegre J, Lefebvre P, Arnaud G (1995) Quantum confinement effects of Cds nanocrystals in a sodium borosilicate glass prepared by the sol gel process. J Appl Phys 77:287

Pal M, Tsujigami Y, Yoshikado A, Sakata H (2000) Electrical and optical properties of $\mathrm{MoO} 3-\mathrm{TeO} 2$ amorphous films prepared by PVD method. Phys Status Solidi (a) 182:727

Shihub SI, Gould RD (1995) Frequency dependence of electronic conduction parameters in evaporated thin films of cobalt phthalocyanine. J Thin Solid Films 254:187

Swelm W, Higazy A, Algradee M (2011) Growth and characterization of novel system of nanoparticles embedded in phosphate glass matrix. World J Condens Matter Phys 1:24-32

Tauc J, Zanini M (1977) Temperature dependence of the absorption edge of liquid sulfur. J Non-Cryst Solids 23:349

Tauc J, Grigorovici R, Vancu A (1966) Optical properties and electronic structure of amorphous germanium. Phys Status Solids $15: 627$ 